\title{
Influence of Sediment Composition, Total Organic Carbon on Benthic Organisms at Pulicat Lagoon: A Case Study
}

Sivaranjani $\mathbf{V}^{*}$, Santhanam $\mathbf{H}$ and Natesan $\mathbf{U}$

Centre for Environmental Studies, Anna University, Kotturpuram, Chennai, Tamil Nadu, India

\begin{abstract}
Benthic environments are dynamic habitats where the sediments, the functional building blocks of the habitat, are continually structured by both the organisms living in and on the seabed as well as by the local physical regime. Benthic animals are an important component of the marine ecological realm and play a large part in marine food chains, organic production and the turnover of sediments and nutrients on the ocean floor. Because the sub-littoral seabed is less subject to variations in tides, swell and wind driven surface currents, the soft sediments of this environment are relatively stable (i.e., unchanging) compared to intertidal and shallow near shore substrates. Similarly, their populations are also more stable and diverse. These biological processes are also inextricably linked with physical variables, thus benthic communities are very susceptible to both natural and anthropogenic changes in the topography and sediment matrix.

Inorder to understand the association between environmental variables and benthic communities, the distribution of benthic organisms in the dynamic mixing zone of Pulicat and the surrounding coastal waters has been studied. The sediment samples obtained from Pulicat were analyzed for sediment composition and total organic carbon. Further the benthic organisms were sorted, enumerated and grouped into different communities. Based on the analysis; it was found that the distribution of benthic organisms varied with the differences in sediment composition and total organic carbon. The mixing of wastewaters from Buckingham canal with the waters of the dynamic zone of Pulicat could be a significant factor influencing the distribution of benthic communities.
\end{abstract}

Keywords: Macrobenthos; Microbenthos; Total organic carbon; Grain size; Pulicat

\section{Introduction}

Semi-enclosed coastal lagoons are interesting environmental laboratories for studies on the relationships of the various ecological factors that define their unique characteristics. They show distinct variations in their physio-chemical environment and biological communities in response to intense anthropogenic excursions in lure of the promise of newer economic capabilities. These productive ecotones are constituted of a mixture of marine, brackish and freshwater indigenous and non-indigenous species of biota. Lagoonal sediments are critically important habitats for study because of their large extent, and the fact that they support a dense and diverse assemblage of organisms. Several researches have shown that the sediments, providing a plethora of microhabitats, call for extensive studies on them and their contributions to the Lagoonal ecology [1].

However, the dwindling numbers of benthic organisms in lagoons due to human interferences has been critically cornered as a major issue of concern. Under such circumstances, a detailed study into the relationships between the biotic and abiotic realms is the need of the hour. The objective of this work is to bring forth the preliminary relationships between two critical sediment logical parameters-Total Organic Carbon and the Grain sizes with the macro faunal and micro faunal benthos in Lagoonal sediments.

\section{Study Area}

The area from the channel entrance of Pulicat lagoon (the second largest brackishwater lagoon in the south-east Indian coast) to the Bay of Bengal (Figure 1) has been selected for our study. This dynamic zone of the lagoon is very often under the greatest physical stress of the tides and waves, combined with the progressive increase in pollution from the wastes brought in from adjoining Buckingham canal. The periodic closure of the mouth of the lagoon has been attributed to continuous supply of silt. This has drastically reduced the water depth, affecting ambient hydrological conditions and decreasing productivity. The absence of dilution by freshwater of the wastes brought in by the Buckingham Canal is attributable to inconsistent run-off from the rivers entering the lagoon.

Keeping these in mind, sampling points have been selected at an interval of $300 \mathrm{kms}$ in the North, East and South of the mouth of the lagoon in addition to a sampling location very near the mouth of the lagoon. It is presumed that, while the former may represent unpolluted marine conditions, the latter could be representative of a slightly polluted brackish water condition.

\section{Methodology}

The sediment samples in the sea were collected using Grab sampler and the along shore sediment samples were collected using core sampler. The surface and bottom water samples and sediment samples were collected in parallel and perpendicular transects at $300 \mathrm{~m}$ from the mouth of the Pulicat lagoon into the open sea (Bay of Bengal) and along the shore at $300 \mathrm{~m}$ interval on April 28, 2005.

Sediment samples were collected and carefully segregated into two

*Corresponding author: Sivaranjani V, Centre for Environmental Studies, Anna University, Kotturpuram, Chennai, Tamil Nadu, India, Tel: 0442235 7004; E-mail: ranjani6147@outlook.com

Received January 01, 2017; Accepted February 14, 2017; Published February 22, 2017

Citation: Sivaranjani V, Santhanam H, Natesan U (2017) Influence of Sediment Composition, Total Organic Carbon on Benthic Organisms at Pulicat Lagoon: A Case Study. J Biodivers Endanger Species 5: 182. doi: 10.4172/2332 2543.1000182

Copyright: (c) 2017 Sivaranjani V, et al. This is an open-access article distributed under the terms of the Creative Commons Attribution License, which permits unrestricted use, distribution, and reproduction in any medium, provided the original author and source are credited. 


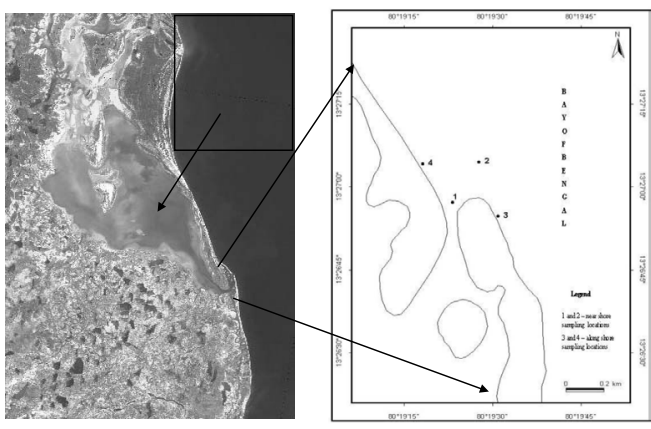

Figure 1: Study area and sampling locations.

labeled polythene covers one for analyzing benthic organisms and the other for total organic carbon analysis. The samples for benthic analysis were preserved using 5\% formalin and the samples for total organic carbon analysis was preserved in ice.

The sediment samples were air dried in clean labeled polyethylene trays and then analyzed for sediment composition i.e., sand: silt: clay ratio by Griffith. The frozen sediment samples for total organic carbon analysis were then air dried and analyzed for percentage of total organic carbon by employing the method devised [2]. Sediment samples were wet-sieved using specified sieves for macro benthic $(500 \mathrm{~m})$ and meiobenthic $(63 \mathrm{~m})$ organisms. The specificity in the sieving procedure lies in the mesh size of the sieves used. The benthic organisms were identified based on the keys and guides available for different groups and then quantified for each sample.

\section{Results}

The total organic carbon in the sampling locations considered for study ranged between 1.1-1.2\%, with the location 3 (300 m south of mouth) recording a maximum value of $1.21 \%$. The organic carbon in the lagoon generally varies from $0.2-1.7 \%$ and the supply of organic carbon $(1.13 \%)$ is reported to be more during post monsoon due to freshwater input. Studies in the past have been conducted to calculate an average accumulation rate for organic carbon in the Pulicat sediments (3.5 $\mathrm{g} / \mathrm{Cm}^{2} /$ year). The average demineralization rate was $12 \mathrm{~g} / \mathrm{Cm}^{2} /$ year,which accounted for around $89 \%$ of the organic carbon deposited in the sediments [3].

From our study, we found that sand (50-80\%) formed the single most predominant component of the substratum in all the locations, followed by silt (10-30\%) and clay (10-30\%) fractions. Previously conducted researches have estimated the percentage of sand, silt and clay in Lagoonal sediments to range between $8-87 \%, 8-78 \%$ and 5-13\% [3].

However the distribution of the macro benthic and meiobenthic organisms was found to be different in different locations. While polychaetes dominated the population of macro benthos at locations 1 and 2 (60 and 35\% respectively), the isopods dominated at location $3(50 \%)$ and, the bivalves and crustaceans (each $25 \%$ ) at location 4. In contrast, the nematodes dominated the meiobenthic populations at three locations-1, 2 and 4 (40, 45 and $40 \%$ respectively) and the flatworms were most dominant at location 3 (40\%). Earlier studies have reported that about 35 living species of benthic organisms have been identified in the lagoon and in each season, six faunal assemblages at an average of $64.5 \%$ of the observed variance emerged from the analysis. Statistical studies have revealed that the most significant assemblage is characterized by Florilus labrodoricum and F. grateloupi (avg. 25.1\%). Crustaceans and copepods are known to dominate the zooplankton population contributing $48.42 \%$ of total zooplankton followed by gastropod and bivalve veliger (45.5\%), tintinnids and foraminiferans (2.93\%) and fish egg masses (1.22\%). The biologically important groups were cladocera, ostracoda, decapoda, rotifera, bryozoa and chaetognatha [4].

Correlation between total organic carbon and benthos as well as grain size fractions with the benthic biota was attempted. Among the macro benthos, the isopods (0.48) showed the maximum correlation with TOC while the amphipods $(-0.91)$ showed the least correlation (Figure 2). Among the meiobenthic forms, the flatworms (0.88) had high correlation with TOC while the nematodes $(-0.90)$ showed the least correlation (Figure 3). Overall correlation with TOC for both groups had highest correlation in the case of flatworms and the least amongst the ostracoda $(-0.88)$.

The crustacean larvae correlated maximum with the percentage of sand (0.98) in the sediments from Pulicat lagoon during our study. The least correlating group was that of the foraminiferans $(-0.63)$. Among the macro benthic fauna, while the crustaceans had the highest correlation (Figure 4), the isopods showed the least (-0.55). Among the meiofauna, the nematodes exhibited greatest correlation $(0.70)$, the foraminiferans correlated the least (Figure 5).

An exactly reverse trend was observed in the correlation between silt and the benthic fauna. The foraminiferans correlated the greatest with silt $(0.83)$ while the crustaceans showed the least $(-0.92)$. Within the macrofaunal group, the polychaetes are distinguished with a good correlation with silt $(0.81)$, whereas the crustacean larvae recorded the least (Figure 6). However an interesting contrast was noticeable among the meiobenthic forms. While the foraminiferans showed greatest

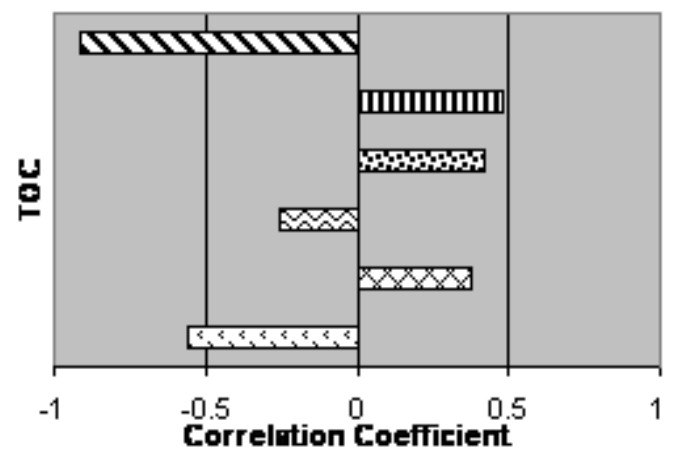

Figure 2: TOC and macro benthos.

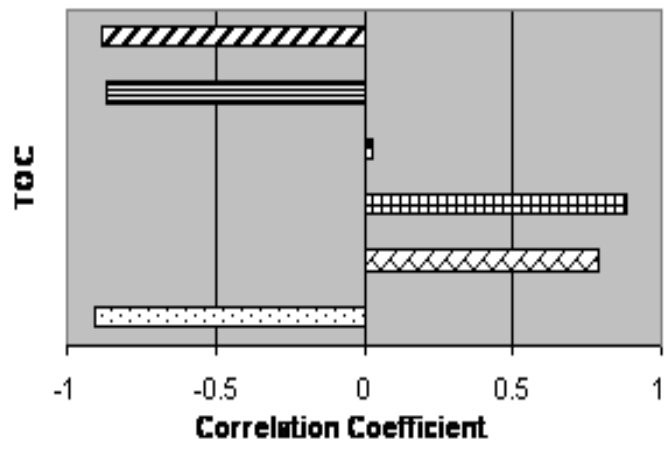

Figure 3: TOC and meiobenthos. 


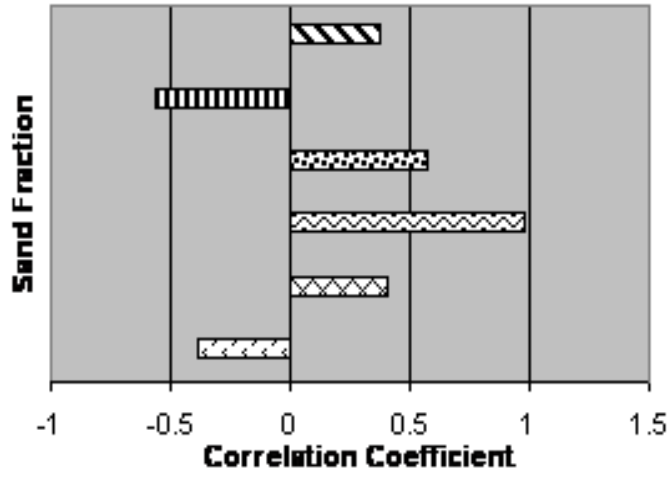

Figure 4: Sand and macrobenthos.

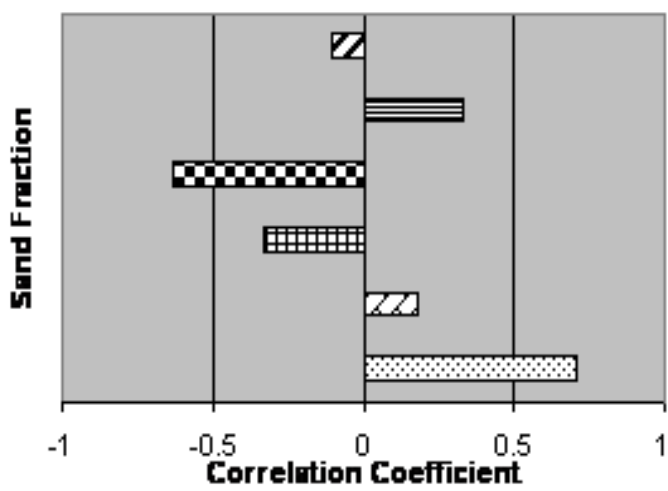

Figure 5: Sand and meiobenthos.

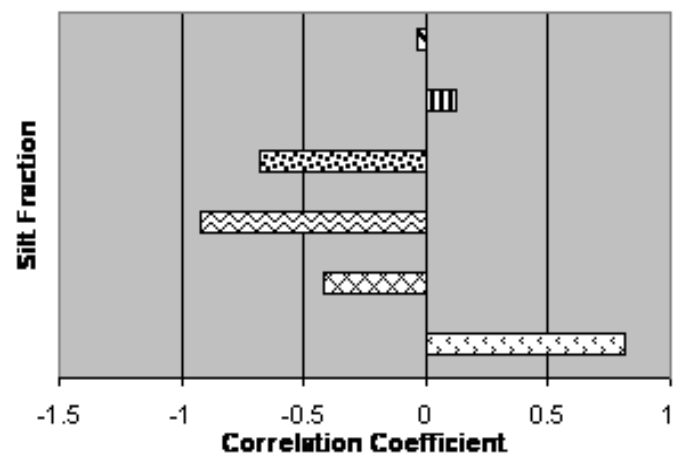

Figure 6: Silt and macrobenthos.

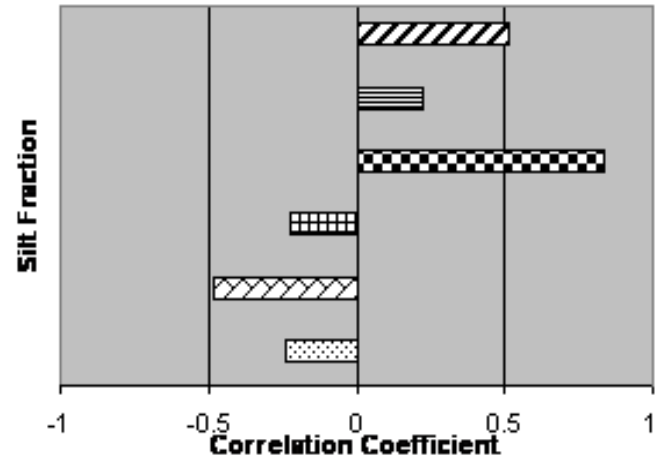

Figure 7: Silt and meiobenthos. correlation with silt, the meiobenthic polychaetes larvae $(-0.47)$ showed the least within the category (Figure 7).

In the case of correlation between the percentage of clay and the benthic organisms, maximum correlation was observed with the isopods (0.77), whereas the least correlation occurred in the case of the nematodes (-0.92). Within the macro fauna, the crustacean larvae remained the least correlating group with clay $(-0.98)$ and the isopods the maximum correlating organisms with clay (Figure 8). Within the meiobenthic fractions, flatworms were seen to possess the maximum correlation (0.68) and nematodes the least (Figure 9).

The spatial dispersion of organisms is a fundamental and characteristic property reflecting the environmental pressures. However, obvious environmental heterogeneity affects choice of a habitat. The above results have highlighted some interesting trends in the distribution of benthic fauna in the lagoon and its surrounding coastal waters. The distribution of the various groups is not uniform and even within groups, strong preferences to selective conditions of TOC content and grain sizes is evident.

Studies on copepods have shown their non-random dispersion at scales of separation from 100 to $1 \mathrm{~cm}$ [5]. Patchy lateral distribution has been observed in the case of living foraminiferans in shallow coastal waters [6]. Variances in the occurrences of polychaetes have been described by many authors. Generally, fine sediments with a high organic and clay content has been favored by deposit feeders in contrast to the filter feeders which reached an optimum abundance in a median grain size of $0.18 \mathrm{~mm}$.

This study showed that, on an average, very low correlation with TOC and clay fractions was observed for the benthic organisms under

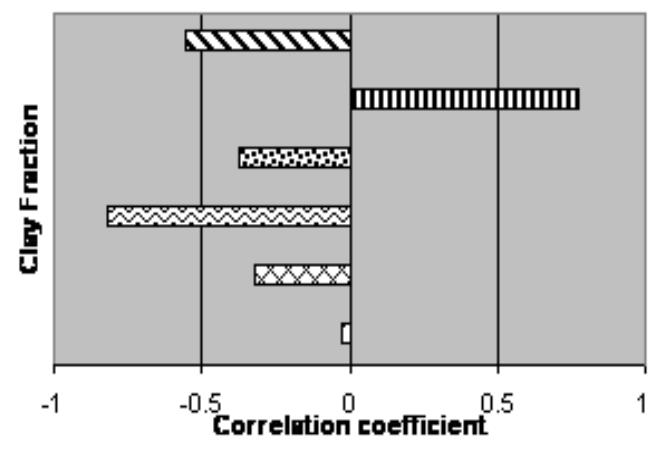

Figure 8: Clay and macrobenthos.

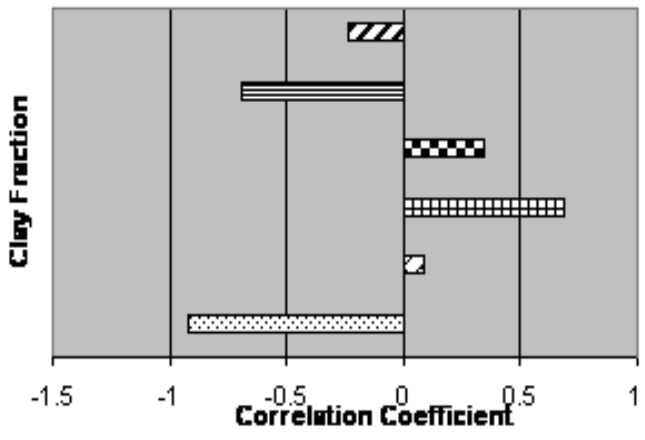

Figure 9: Clay and meiobenthos. 
Citation: Sivaranjani V, Santhanam H, Natesan U (2017) Influence of Sediment Composition, Total Organic Carbon on Benthic Organisms at Pulicat Lagoon: A Case Study. J Biodivers Endanger Species 5: 182. doi: 10.4172/2332-2543.1000182

Page 4 of 4

study, while correlation with the sand fractions showed the greatest correlation. Such trends can be explained complex relationships between the tidal and wave-induced patterns of water and sediment movement in near-shore environments such as our area of study. It is generally presumed that characteristic macrofaunal organisms with higher abundance and biomass prefer a wide range of microhabitats within erosive and depositional habitats. Our study has proved this fact since a greater dominance macrofaunal groups at locations of greater dynamicity (locations $1,4,3$ ) was observed in comparison compared with the meiofauna.

However, the meiofauna with a general preference for fine sediments and high organic content are represented at location 1 . This may suggest that the meiobenthic groups could also possess certain preferential microhabitats within a low-TOC and high-sand dominated habitat.

This important finding implies two possible outcomes. The load of wastes carried into the lagoon by the Buckingham canal has a very slight representation even at the mouth of the lagoon during dry seasons when the dilution of wastewaters does not occur. This is supported by the fact that a good percentage of benthic pollution indicators (polychaetes, nematodes etc.) are present near the mouth of the lagoon. Secondly, the benthos of the Pulicat lagoon and its coastal waters has adapted to seasonal and spatial niche selection as a consequence of the constantly shifting substratum at these dynamic locations and alterations hydrological chemistry of the lagoon. Further studies into

\section{Conclusion}

The study gives us an indication of the existence of different habitats of preference for the major macro faunal and meiobenthic organisms inhabiting the area of interest. Further, the monitoring of the substratum and its biotic components at the dynamic channel of the lagoon as well as its adjoining coastal stretch could help in a better understanding of the distribution of the benthos and the ecological roles they perform there.

\section{References}

1. Lagoons of India State-of-the-art Report (2001) ENVIS Publication Series: 3/2001 Environmental Information System Centre, Centre of Advanced Study in Marine Biology.

2. Henri EG, Wilson RF, Lois T, David WF (1974) An Inexpensive Titration Method for the Determination of Organic Carbon in Recent Sediments. J Sediment Petrol 44: 249-253.

3. Jayaraju N, Suryakumar T, Reddy KR (2000) Living benthic foraminiferal assemblages of Pulicat lake, east coast of India. J Geol Soc 56: 331-339.

4. Padma S, Periakali P (1999) Physico-chemical and geochemical studies in Pulicat lake, east coast of India. Indian J Mar Sci 28: 434-437.

5. David T (1978) Harpacticoid Copepods and Biogenic Structures: Implications for Deep-Sea Diversity Maintenance 1978. Ecological Processes in Coastal and Marine Systems 10: 217-231.

6. Charles T (1971) Sampling and spatial distribution of bentiionic foraminifera Limnology and Oceanography. 